Conclusion With the overall detection rate of $87.2 \%(63.5 \%$ bilateral and $24.0 \%$ - unilateral) we find SLB ICG procedure feasible. Most frequently SLs were detected in the external iliac region. Age and extragenital pathology are the statistically significant factors associated with the failure of SLB procedure.

\section{ROLE OF THREE-DIMENSIONAL TRANSVAGINAL ULTRASOUND AND DIFFUSION-WEIGHTED MAGNETIC RESONANCE IMAGING FOR ASSESSMENT OF MYOMETRIAL INVASION IN PATIENTS WITH LOW-RISK ENDOMETRIAL CANCER}

${ }^{1}$ Núria Carreras Diéguez, ${ }^{1}$ Isabel Matas, ${ }^{2}$ Crístian de Guirior, ${ }^{2}$ Meritxell Munman ${ }^{1}$ Pere Fusté, ${ }^{1}$ Núria Agustí, ${ }^{1}$ Ariel Glickman, ${ }^{1}$ Berta Diaz-Feijoo, ${ }^{1}$ Jaume Pahisa, ${ }^{1}$ Aureli Torne. ${ }^{1}$ Hospital Clínic de Barcelona; Gynecologic Oncology Unit; ${ }^{2}$ Hospital Clínic de Barcelona; Gynecology and Obstetrics

\subsection{6/ijgc-2020-ESG0.67}

Introduction/Background In patients with early-stage, grade 12, endometrioid endometrial cancer, preoperative assessment of myometrial invasion is essential to define the need of pelvic and paraaortic lymph node dissection. Our aim was to evaluate the role of three-dimensional transvaginal ultrasound (3D-TVUS) and diffusion-weighted magnetic resonance imaging (DW-RMI) for the assessment of myometrial invasion in patients with low-risk endometrial cancer.

Methodology We performed a single center retrospective study, including patients who underwent surgery for grade 1-2 endometrioid endometrial cancer, FIGO stage I-II, in Hospital Clínic de Barcelona between 2010 and 2019. We computed sensitivity, specificity, and predictive values of 3D-TVUS and DW-RMI, as well as of intraoperative frozen section pathological study of surgical specimen, for diagnosis of deep myometrial invasion $(\geq 50 \%)$. Definitive pathological analysis of surgical specimen was considered gold standard for diagnosis of deep myometrial invasion.

Results One hundred and fifty-three patients were included, $120(78.43 \%)$ patients presented myometrial invasion $<50 \%$ in postoperative analysis of surgical specimen and 33 (21.57\%) patients presented deep myometrial invasion. Sensitivity and specificity of 3D-TVUS for diagnosis of deep myometrial invasion was $68.8 \%$ and $80.5 \%$ respectively, while DW-RMI showed a sensitivity and specificity of $76.2 \%$ and $84.4 \%$. When combining both techniques (we considered that a patient had deep myometrial invasion when 3D-TVUS or DW-RMI - or both of them - showed deep myometrial invasion), sensitivity was $93.1 \%$ and specificity was $68.4 \%$. The proportion of patients with uterine fibroids was higher in the group of patients with false negative $(60 \%)$ or false positive $(39.13 \%)$ result in 3D-TVUS, although these results did not reach statistical significance. Regarding the intraoperative frozen section pathological study of surgical specimen, it showed a sensitivity of $75 \%$ with specificity of $96.4 \%$ for diagnosis of deep myometrial invasion.

Conclusion The combination of 3D-TVUS and DW-RMI offers a better sensitivity, higher than intraoperative frozen section pathological study of the surgical specimen, for the diagnosis of deep myometrial invasion in patients with early-stage, grade 1-2, endometrioid endometrial cancer. Such information may be useful in selecting patients who require lymph node dissection.

Disclosures The authors of this abstract have no disclosures.

\section{CLINICAL PARAMETERS PREDICTING RISK OF CONCURRENT INVASIVE CARCINOMA AND HIGH-RISK CARCINOMA IN PATIENTS WITH ENDOMETRIAL INTRAEPITHELIAL NEOPLASIA}

Nazlı Orhan', Raziye Melike Yildirim', Halise Meltem Batur', Utku Akgor², Nejat Ozgul', Murat Gultekin', Mehmet Coskun Salman'. 'Hacettepe University Faculty of Medicine; Department of Obstetrics and Gynaecology; ${ }^{2}$ Hacettepe University Faculty of Medicine; Department of Gynecological Oncology; Department of Obstetrics and Gynaecology

\subsection{6/ijgc-2020-ESGO.68}

Introduction/Background Endometrial intraepithelial neoplasia (EIN) is a premalignant lesion, but risk of concurrent endometrial adenocarcinoma (EAC) is also high. Although most patients with EIN diagnosed with concurrent EAC will have low risk disease, some will have high-risk disease who require. Clinical characteristics may help determine such patients.

Methodology Patients with a diagnosis of EIN who were operated at Hacettepe University Faculty of Medicine, Department of Obstetrics and Gynaecology were identified. The rate of concurrent EAC and high-risk EAC were determined. Preoperative characteristics were reviewed in order to determine the predictors of concurrent malignancy.

Results A total of 252 patients constituted study group. Mean age was 46.6 years and $43.7 \%$ were postmenopausal. $44.0 \%$ had co-existing one or more medical diseases while $14.3 \%$ had diabetes, $19.5 \%$ had hypertension, and $7.5 \%$ had both. The most common surgery was total hysterectomy with or without adnexal removal performed in $93.6 \%$ of patients. Frozen section was requested for $82.5 \%$ of patients. Final pathology revealed EAC in $17.5 \%$, but only $4.4 \%$ had highrisk disease. The accuracy of frozen section for predicting final pathology in terms of the presence or absence of EAC was $89.4 \%$. Patient with malignancy tend to be significantly older (47.4 vs. 54.1 years, $\mathrm{p}=0.02)$ and risk of malignancy was significantly higher in postmenopausal women $(9.2 \%$ vs $28.2 \%, \mathrm{p}<0.001)$ and in women with hypertension $(13.8 \%$ vs $32.7 \%, \mathrm{p}=0.02)$. similarly, patients with high-risk disease were significantly older (48.2 vs. 58.2 years, $\mathrm{p}=0.01$ ) and this risk was higher in postmenopausal women $(1.4 \%$ vs. $8.2 \%$, $\mathrm{p}=0.01)$ and women with hypertension $(3.0 \%$ vs. $10.2 \%$, $\mathrm{p}=0.04)$.

Conclusion Surgery is the mainstay of treatment in patients with EIN. During surgery, frozen section evaluation should be requested since a significant proportion of patients have concurrent EAC and frozen section is highly effective in determining these patients. Although rare, some patients may have concurrent high-risk endometrial carcinoma necessitating surgical staging. Both concurrent invasive carcinoma and high-risk disease are associated with older age, being in postmenopausal period, and having hypertension.

Disclosures No potential conflict of interest to declare.

\section{ENDOMETRIAL BIOPSIES: FOR WHOM AND WHEN?}

Bilal Esat Temiz, ${ }^{1}$ Esra Karataş, ${ }^{2}$ Utku Akgor, ${ }^{3}$ Murat Gultekin, ${ }^{3}$ Mehmet Coskun Salman, ${ }^{1}$ Nejat Ozgul. ${ }^{1}$ Hacettepe University Hospital; Obstetrics and Gynecology; ${ }^{2}$ Hacettepe University Faculty of Medicine; Department of Gynecological Oncology; Department of Obstetrics and Gynaecology; ${ }^{3}$ Hacettepe University Faculty of Medicine; Department of Obstetrics and Gynaecology

10.1136/ijgc-2020-ESGO.69 
Introduction/Background To evaluate the role of transvaginal sonographic (tvUSG) endometrial thickness to detect endometrial cancers among postmenopausal women.

Methodology Endometrial biopsy results of 1099 postmenopausal patients who have been evaluated at our hospital since 2015 are retrospectively collected. Age, symptoms (asymptomatic vs. postmenopausal bleeding-PMB), tvUSG endometrial thickness were the parameters to be collected. Patients with insufficient endometrial sampling were excluded $(\mathrm{n}=103$,

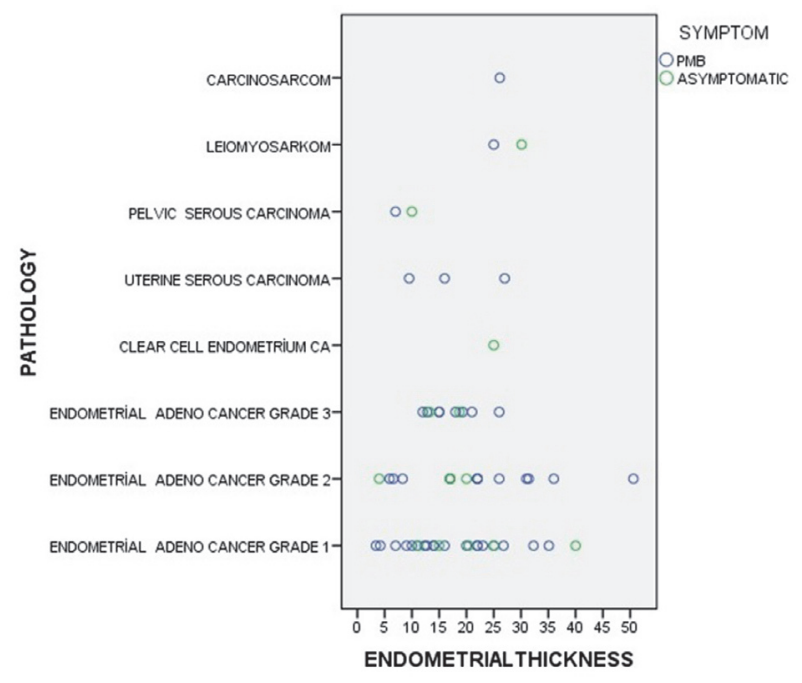

Abstract 357 Figure 1 Scatter plot graph comparing the endometrial pathologies vs. tvUSG thickness

\begin{tabular}{|c|c|c|c|}
\hline & $\begin{array}{l}\text { Patients with post-menopausal } \\
\text { bleeding } \\
(\mathbf{n}=(40) \\
n(9.6)\end{array}$ & $\begin{array}{c}\begin{array}{c}\text { Asymptomatic post- } \\
\text { menopausal patients } \\
(\mathrm{n}=356) \\
\mathrm{N}(96)\end{array} \\
\end{array}$ & $P$ Value \\
\hline \multicolumn{4}{|r|}{$<0.05$} \\
\hline 250 & $150(23.4)$ & $57(16)$ & \\
\hline 50.59 & $317(49.5)$ & $153(43)$ & \\
\hline $60-69$ & $107(16.7)$ & $107(30)$ & \\
\hline 570 & $66(10.3)$ & $39(11)$ & \\
\hline \multicolumn{3}{|l|}{ ENDOAETRIMI THCKNESS } & \multirow[t]{5}{*}{, 000} \\
\hline$\leq$ & $176(27.5)$ & $63(177)$ & \\
\hline $0-10$ & 251 (39.2) & $141(39.6)$ & \\
\hline 11-19 & $167(26.1)$ & $1199(33.4)$ & \\
\hline$\geq 20$ & $46(72)$ & $33(9.3)$ & \\
\hline \multicolumn{3}{|l|}{\begin{tabular}{|l} 
PATHOLOGY \\
\end{tabular}} & \multirow[t]{6}{*}{30.05} \\
\hline $\begin{array}{l}\text { BENGN/ PHYSTOLOOGICAL } \\
\text { ENDOMETRTUM(GROCPA) }\end{array}$ & $415(64.8)$ & $231(64.9)$ & \\
\hline ENDOMETRAAL POLYP (GROUP B) & $148(23.1)$ & $101(28.3)$ & \\
\hline $\begin{array}{l}\text { ENDOMETRIAL INTRAEPTTHELIAL } \\
\text { HYPERPLASIA (GROUPC) } \\
\end{array}$ & $28(4.3)$ & $9(2.5)$ & \\
\hline $\begin{array}{l}\text { ENDOMETRROID TYPE ENDOMETRtAL } \\
\text { CACNOOMA (OROUPD) }\end{array}$ & $40(6.2)$ & $11(3.0)$ & \\
\hline $\begin{array}{l}\text { NON-ENDOMEITRIOD TYPE } \\
\text { ENDOAETRAAL CACINOMA (GROUP E) }\end{array}$ & 9 (1.) & $4(1.3)$ & \\
\hline CANCER DETECTION & $49(7.9)$ & $15(4.2)$ & $<0.05$ \\
\hline \multicolumn{3}{|l|}{ TUMOR GRADE } & \multirow[t]{3}{*}{20.05} \\
\hline HIOH ORADE & $15(30,6)$ & 5(33.3) & \\
\hline LOW GRADE & $34(69.4)$ & $10(66.7)$ & \\
\hline
\end{tabular}

9.3\%). Remaining study group $(\mathrm{n}=996)$ were divided into 5 groups according to their histopathological diagnosis: benign/ physiological endometrium (group A), endometrial polyp (group B), endometrial hyperplasia or intraepithelial neoplasia (group C), endometrioid carcinoma (group D) and non-endometrioid carcinoma (group E). A scatter plot graph (figure 1) is prepared comparing the endometrial pathologies vs. tvUSG thickness.

Results A total of 996 endometrial biopsies were evaluated (356 patients were asymptomatic, 640 patients presented with postmenopausal bleeding). The median age of the patients was 57.3 years. The cancer detection rate among patients with bleeding was $7.6 \%$ (49/640). This rate was $4.2 \%$ in asymptomatic patients (15/356). The comparison of the two groups is presented in table 1 . High-grade cancers were detected three times more in symptomatic patients $(75 \%, 15 / 20$ vs. $25 \%, 5 / 20)$.

The mean endometrial thickness increases gradually from group A to group B: 8.3 for group A; and 12.1, 11.9, 18.7 and $16.0 \mathrm{~mm}$ for groups $\mathrm{B}, \mathrm{C}, \mathrm{D}$, and $\mathrm{E}$; respectively. In groups $\mathrm{D}$ and $\mathrm{E}$, there were only 4 patients with an endometrial thickness of less than $5 \mathrm{~mm}$ (6.2\%). Three patients were symptomatic and only one patient was asymptomatic.

A threshold of $5 \mathrm{~mm}$ can reveal $14 / 15$ cancers in asymptomatic patients, while this figure is $12 / 15$ for a $10 \mathrm{~mm}$ threshold and 6/15 for a threshold of 20 (figure 1). A threshold for $10 \mathrm{~mm}$ is reasonable for asymptomatic patients, missing 3 cancer patients (1 low grade, 2 high grade). In symptomatic patients, these figures were $46 / 49$ for $5 \mathrm{~mm}$ threshold (3 missed cancer), $37 / 49$ for a $10 \mathrm{~mm}$ threshold (12 missed cancer) and 21/49 for a $20 \mathrm{~mm}$ threshold (28 missed cancer).

Conclusion Endometrial biopsy should be performed routinely in patients with postmenopausal bleeding due to high numbers of missed cancers. However, in asymptomatic patients, a biopsy can safely be ignored in patients with endometrial thickness of less than $5 \mathrm{~mm}$. A biopsy may also be reserved for patients with an endometrial thickness $>10 \mathrm{~mm}$ (Cancer detection rate is $1.4 \%$ vs. $7.8 \%$ ).

Disclosures Nothing to declare.

\section{PHASE-SPECIFIC AND LIFETIME COSTS OF CERVICAL AND ENDOMETRIAL CANCER AMONG COMMERCIALLY INSURED PATIENTS IN THE UNITED STATES}

${ }^{1}$ Ruchitbhai Shah, ${ }^{1}$ Nehemiah Kebede, ${ }^{1}$ Anuj Shah, ${ }^{2}$ Shelby Corman, ${ }^{3}$ Chizoba Nwankwo. ${ }^{1}$ Pharmerit - an Open Health Company; Pharmerit International, Bethesda, MD, USA; ${ }^{2}$ Pharmerit; Pharmerit - an Open Health Company; USA; ${ }^{3}$ Merck and Co., Inc

\subsection{6/ijgc-2020-ESG0.70}

Introduction/Background There are little data describing the economic burden of cervical/endometrial cancers. Therefore, this study aimed to estimate the incremental lifetime economic burden among newly diagnosed cervical and endometrial cancer patients versus non-cancer controls using a phase-based costing approach.

Methodology Cervical and endometrial cancer patients newly diagnosed between January 2015 - June 2018, with continuous enrollment for 12 months prior and 6 months post diagnosis were identified in the Optum Clinformatics DataMart database. Non-cancer controls included patients who did not have any cancer diagnosis and had at least 18 months of continuous enrollment in the data. The index date was the date of the first diagnosis for cancer cases and the first claim date 